\section{A avaliação do livro didático como tema da formação inicial do professor de língua portuguesa}

The evaluation of the textbook as a theme of the initial training of the Portuguese language teacher

Adair BONINI (UFSC) adair.bonini@gmail.com

Daniella de Cássia YANO (UFSC) daniella.yano@ifsc.edu.br

Recebido em: 29 de jan. de 2018. Aceito em: 20 de jun. de 2018.
BONINI, Adair; YANO, Daniella de Cássia. A avaliação do livro didático como tema da formação inicial do professor de língua portuguesa. Entrepalavras, Fortaleza, v. 8, n. 2, p. 323-343, maio/ago. 2018

Resumo: Na atual conjuntura de disponibilidade e uso do livro didático na rede básica de ensino, cabe aos cursos de formação inicial de professores dar alicerce a uma avaliação e uso mais crítico desse recurso. Este trabalho objetiva contribuir com reflexões sobre o processo de escolha dos livros didáticos de língua portuguesa de ensino médio nas escolas, verificar o quanto o questionário do PNLD/2018 viabiliza essa dinâmica e pensar como esse tema pode ser tratado na formação inicial de professores. Com o intuito de fomentar discussões nos cursos de licenciatura e auxiliar o futuro docente na avaliação e bom uso do material, este ensaio ainda sugere um quadro com questões que envolvem o conteúdo basilar de língua portuguesa e a realidade da prática de sala de aula.

Palavras-chave: Livro didático. Formação docente. Língua portuguesa. 
v. $8(2)$

$323-343$

mai/ago 2018

Abstract: In the present scenario of availability and use of the textbook in the basic education network, the initial training courses for teachers shall provide the support for the evaluation and a more critical use of this resource. This work aims to contribute with reflections on the process of choice of textbooks of Portuguese for high school, check whether the PNLD/2018 questionnaire enables this dynamic and consider how this theme can be studied in the initial training of teachers. With the purpose of fostering discussions in the graduation courses and helping the future teacher in the evaluation and good use of the material, this work also suggests a framework with questions which involve the basic content of the Portuguese language and the reality of the teaching in the classroom.

Keywords: Textbook. Teacher training. Portuguese language.

\section{Introdução}

Ao longo das últimas décadas, muitos pesquisadores ${ }^{1}$, em diferentes áreas e abordagens, têm se debruçado sobre os mais diversos aspectos referentes ao livro didático, o que tem, apesar das críticas que recebe, colaborado para o aprimoramento em seu conteúdo e qualidade. Também tem se revelado eficaz, nesse sentido, a criação do Programa Nacional do Livro Didático (PNLD), política adotada pelo Estado em que o governo federal assume a responsabilidade pelo planejamento, avaliação, compra e distribuição gratuita dos livros para os alunos da Educação Básica da rede pública.

Ainda assim, apesar das inúmeras e relevantes pesquisas ${ }^{2}$ em torno do livro didático, de ser o recurso mais utilizado em sala de aula e foco de políticas públicas, ele não tem lugar garantido nas discussões dos cursos de licenciatura, salvo quando abordado entre os demais conteúdos de uma ou outra disciplina. Em cursos de formação continuada e pós-graduação, o tema tem sido um pouco mais recorrente.

Esse cenário de discrepância entre o uso do livro didático e a formação de professores foi motivação para este ensaio, aportando sugestões de como abordar tal recurso em termos de formação docente no que se refere à análise, escolha e uso do livro didático. Enfocamos aqui, mais especificamente, o livro didático de língua portuguesa voltado para o ensino médio.

\footnotetext{
${ }^{1}$ Como exemplificação, de 2013 a 2017, a área de Linguística, Letras e Artes produziu 588 pesquisas entre teses e dissertações com o tema "livro didático", conforme resultado de busca no catálogo de teses e dissertações da Capes.

2 Nosella (1981), Lajolo (1996), Freitag; Costa; Mota (1997), Faria (1998), Coracini (1999), Batista (2001), Rojo; Batista (2003), Dionísio; Bezzera (2003), Cassiano (2007), Antunes (2012), Munakata (2012; 2016); Batista; Silveira (2016). Mencionamos aqui somente alguns exemplos, tanto clássicos quanto recentes, sem qualquer pretensão de formular uma lista exata e única de referências.
} 
Para tratar do tema, consideramos fundamental, inicialmente, apresentar o contexto de políticas públicas em torno do livro didático. Compreendendo esse quadro de institucionalização do material, é possível propormos reflexões a respeito do processo de formação docente em termos desse quesito. Por fim, lançaremos olhares sobre alguns pontos do livro didático de língua portuguesa, com o propósito de auxiliar na formação de professores, e de dar apoio diretamente aos docentes que fazem uso desse material.

\section{Contexto das políticas públicas do livro didático}

Tendo por fonte o histórico do FNDE (BRASIL, 2017), buscamos inicialmente tecer alguns comentários de fatos históricos que julgamos relevantes para perceber a relação do Estado com o livro didático. Tomamos o ano de 1938 para frisar que é quando o livro didático entra na ordem de assuntos do governo Getúlio Vargas, por meio do decreto-lei $n^{0}$ 1.006, que estabelece as condições de produção, importação e utilização do livro didático. Surge então uma primeira comissão responsável por: examinar e julgar os livros, autorizando-os para o uso ou não; estimular sua produção; e indicar livros estrangeiros.

Outra data pertinente é o ano de 1945, em que, pelo Decreto-Lei $n^{0} 8.460$, é permitido ao professor a escolha do livro, a partir da relação oficial das obras de uso autorizado pelo governo. A lista provinha da avaliação feita pela Comissão Nacional do Livro Didático, cujos critérios estabelecidos não são distantes dos atuais editais do PNLD.

Um momento que também esclarecedor dessa história diz respeito à produção, edição e distribuição gratuita dos livros nas escolas, que acontece em 1966, quando foi criada a Comissão do Livro Técnico e Livro Didático, por um acordo entre o Ministério da Educação (MEC) e a Agência Norte-Americana para o Desenvolvimento Internacional (Usaid). Em 1971 esse convênio é desfeito, implantando-se o sistema de contribuição financeira das unidades federadas para o Fundo do Livro Didático, e o Instituto Nacional do Livro (INL) passa a desenvolver o Programa do Livro Didático para o Ensino Fundamental. Mas em 1976, então com a Fundação Nacional do Material Escolar (Fename) responsável pela execução do programa do livro didático, os recursos insuficientes impedem o atendimento aos alunos do ensino fundamental da rede pública. 
v. 8 (2)

$323-343$

mai/ago 2018
Em 1983, inclui-se o ensino fundamental no programa e o professor participa da escolha dos livros. E em 1985 emerge efetivamente o Programa Nacional do Livro Didático (PNLD) que traz, dentre outros apontamentos, a indicação do livro didático pelos professores e sua reutilização. Ao longo dos anos, o Programa passou por dificuldades e em alguns estágios a distribuição dos livros foi comprometida pelo orçamento.

Em 1994 são definidos critérios para avaliação dos livros didáticos, e de 1995 a 1997, firma-se a distribuição dos livros didáticos no ensino fundamental e são incorporadas ao Programa as seguintes mudanças: fluxo regular de verbas para aquisição das obras, definições de critérios de avaliação dos livros e publicação do Guia de Livros Didáticos. Também desde essa época, a política de execução do PNLD é de responsabilidade do Fundo Nacional de Desenvolvimento da Educação (FNDE), órgão que amplia sua área de atuação e distribui ainda dicionários, inclusive em Libras e Braile, e obras literárias destinadas aos acervos das bibliotecas escolares de Ensino Fundamental, por meio do Programa Nacional da Biblioteca Escolar (PNBE).

Em 2003, é criado o Programa de distribuição de livros didáticos para o Ensino Médio (PNLEM). As distribuições ocorreram de forma gradual na contemplação das disciplinas, seguidas por reposições e complementações dos livros que já haviam sido distribuídos. Ou seja, a inclusão dos componentes curriculares no programa deu-se em etapas. Em 2012, é incluída a modalidade de jovens e adultos (EJA) e, no PNLD de 2015, completa-se a distribuição dos livros das disciplinas básicas: português, matemática, história, geografia, física, química, biologia, filosofia, sociologia, língua estrangeira e artes (BRASIL, 2017).

Do ponto de vista econômico, cabe comentarmos as vultosas cifras de 2017. O investimento nesse ano foi de quase $\mathrm{R} \$ 1,3$ bilhão, para distribuir 157 milhões de exemplares para 32 milhões de alunos dos anos finais do Ensino Fundamental, além de repor e complementar exemplares para os anos iniciais, para o ensino médio e atendimento ao EJA. Em 2018, os investimentos voltam-se para o Ensino Médio e reposição dos demais segmentos (BRASIL, 2017a). Não se pode deixar de mencionar a importância do financiamento de materiais didáticos para as escolas públicas, mas também que a distribuição de livros didáticos pelo MEC está vinculada aos objetivos econômicos das editoras, nem todas brasileiras, e que o Brasil é um dos maiores compradores de livros didáticos do mundo (CASSIANO, 2007). 
Cabe notar também as políticas de gerenciamento dos livros didáticos, incluindo medidas para orientação da escolha pelo docente, a fim de que esta não fique somente a cargo de estratégias promocionais e coerção das editoras. Assim, em 1996, o Ministério da Educação (MEC) oficializou a avaliação pedagógica dos livros didáticos comprados por meio do PNLD (BRASIL, 2017). Nessa década é promulgada a Lei de Diretrizes e Bases da Educação Nacional (LDB) (BRASIL, 1996) e são publicados os Parâmetros Curriculares Nacionais (PCN) (BRASIL, 1997). A avaliação dos livros didáticos, com o objetivo de aprimorar a Educação Básica, tem atualmente, entre outros critérios, as diretrizes da LDB e dos PCN como norteadores, além das Diretrizes Curriculares Nacionais para a Educação Básica (DCN) (BRASIL, 2013).

Esse processo de avaliação dos livros didáticos já passou por várias etapas, incluindo sua classificação pelo número de estrelas que recebiam dos avaliadores. Hoje, são classificados somente como aprovados ou não, sendo que os reprovados não são divulgados, como acontecia anteriormente. As avaliações pedagógicas eram realizadas por instituições públicas de educação superior até 2017; para o PNLD de 2019, toda a gestão passa a ser de responsabilidade do MEC, inclusive a seleção dos coordenadores e avaliadores.

O resultado tem sido, nos últimos anos, a publicação de uma resenha das obras aprovadas no Guia de Livros Didáticos, que é enviado às escolas e, mais recentemente, também disponibilizado na Internet, com o intuito de ser insumo para os professores na escolha do livro didático a ser adotado em sua escola.

O processo de escolha dos livros pelos docentes ainda tem muitos entraves, como prazos insuficientes para reuniões, debates e um olhar mais aprofundado do professor. Não raro, o professor acaba optando pelo livro alvo de marketing de alguma editora. Por hora, o docente tem acesso online apenas ao Manual do Professor de cada obra para auxiliá-lo na decisão. Para o próximo processo, a proposta do PNLD é de que o professor tenha acesso a todo o conteúdo das obras de forma integral. Esse contato com o livro vai qualificar o processo de escolha (BRASIL, 2017b).

Acrescentamos que cada processo de avaliação parte de um edital específico (BRASIL, 2015a). No referido documento são dadas diretrizes para que as editoras participem do sistema de inscrição a fim de que suas obras sejam avaliadas e recomendadas. Há indicações no edital de como os livros devem trazer seus conteúdos e o que devem 
V. $8(2)$

$323-343$

mai/ago 2018

evitar, assim, a participação no processo requer das editoras, a cada edital, um constante retrabalho, e possível aprimoramento em relação à qualidade pedagógica desse material.

Não há como negar que a avaliação tem buscado a qualidade dos livros, já que são excluídos aqueles que evidenciam erros conceituais, preconceitos, falta de ética e democracia, inadequação da abordagem teórico-metodológica entre outros tantos critérios. Por outro lado, há uma certa homogeneização quanto ao formato e conteúdo dos livros.

Para os próximos processos, o PNLD tem o intuito de acrescentar livros para Educação Infantil, Educação Física e Projeto Integrador, este último para trabalhar os componentes curriculares de forma integrada. Há também previsão de distribuição de softwares e jogos educacionais. Muda-se, além disso, o ciclo de renovação das obras, que passará de três para quatro anos. Outra novidade é que os livros do ensino fundamental não serão mais reutilizáveis e sim consumíveis; eles pertencerão aos alunos que poderão fazer as atividades no próprio material, o que já acontece com os livros de filosofia, sociologia e arte (BRASIL, 2017b).

Quanto aos livros didáticos de língua portuguesa do ensino médio, objeto de nosso estudo, onze coleções foram aprovadas e constam no Guia de Livros Didáticos do PNLD de 2018 (BRASIL, 2017c). O Guia traz uma resenha de cada coleção, contendo as seguintes etapas: a) Visão geral: indica os pontos fortes e fracos da coleção, o que a diferencia, como projetos, e dá sugestões ao professor de complementação de conteúdos e atividades, quando ausentes da obra; b) Descrição: contém informações sobre a estrutura e o formato do livro, como é dividido, o que encontrar em seus capítulos e seções, como essas partes estão interligadas, como se dá a sequência didática e que conteúdos contempla; c) Análise da obra: detalha como o livro aborda a leitura, a literatura, a produção textual, a oralidade, os conhecimentos linguísticos e o manual do professor; e d) Em sala de aula: sugestões sobre o uso do livro didático, um tópico inovador e necessário. Ou seja, trata-se de um guia muito mais elaborado e rico em detalhes que o anterior, de 2014, que realmente não só faz apontamentos, mas leva a reflexões sobre o ensino e aprendizagem de língua portuguesa.

Depois de percorrermos o contexto do livro didático no que se refere a instâncias governamentais, cabe refletirmos sobre a formação que o professor tem para estar apto a escolher e fazer bom uso desse recurso em sala de aula. 


\section{Uso do livro didático e formação do professor}

O uso do livro didático pelo professor não é um assunto novo entre os pesquisadores ${ }^{3}$ em uma discussão que ganha corpo e criticidade ao longo do tempo. Há defesas de seu uso, mas também críticas a favor de sua abolição. É interessante que o professor prepare o seu próprio material, como forma de elaboração didática crítica e de respeito ao estudante como interlocutor situado. Talvez os recursos públicos também pudessem ser destinados a esse fim. Apesar disso, a adoção de um material pertinente somado a uma prática pedagógica autônoma, crítica e criativa também possa resultar em ensino e aprendizagem significativos para os estudantes.

Diferente do livro didático, que tem passado por intensos debates e inovações, a formação inicial do professor, apesar das discussões e críticas, ainda precisa passar por transformações que possam garantir uma formação mais ajustada às práticas profissionais docentes, aos contextos específicos de mediação pedagógica e às necessidades de aprendizagem e reflexão dos estudantes (KLEIMAN, 2007).

Nóvoa e Vieira (2017) defendem que é preciso haver uma "formação para uma profissão", que não são implicações distintas, pois a formação não deve ser voltada somente para a teoria, nas universidades, assim como a profissão não dever ser totalmente referente à prática, nas escolas. A partir dessa ponderação, concebemos que as licenciaturas devem formar para a prática em sala de aula (com fundamentação na teoria), e não se constituir como um bacharelado disfarçado, deixando, à margem do curso, a prática e uma visão mais real do cotidiano da profissão docente. Do mesmo modo, a escola é lugar de reflexões, discussões e estudos teóricos, alicerçados na prática, de trabalho colaborativo e não de uma rotina trivial sem capacidade de inovação. Os autores ainda acrescentam que não se trata de uma profissão técnica, com soluções racionais e objetivas.

A docência baseia-se sempre numa resposta contextualizada,
em situação, diferente de uma sala de aula para outra, diferente
de um aluno para outro. Um professor atua sempre num quadro
de incerteza, de imprevisibilidade. Muitas vezes não sabemos
tudo, não possuímos todos os dados, mas, ainda assim, temos
de decidir e agir. [...] para conseguirem estar à altura do
momento têm de estar muito bem preparados (NÓVOA; VIEIRA,
2017, p. 37).

3 Em 1987, Freitag, Motta e Costa apontaram na obra Estado da arte do livro didático no Brasil pesquisas sobre a relação do professor com o livro didático. 
v. $8(2)$

$323-343$

mai/ago 2018

Inspirados nas ideias dos autores, podemos dizer que as teorias de ensino e aprendizagem devem procurar aproximar o graduando de sua prática, da rotina da profissão docente, que tem o livro didático como um importante recurso da sala de aula. A avaliação de material didático publicado por editoras é parte fundamental desse processo, e envolve a reflexão do contexto histórico, social, político e ideológico que abarca seu uso em sala de aula e se reflete na postura docente. Desse modo, em um curso de formação inicial, a leitura crítica dos documentos oficiais referentes às políticas públicas voltadas ao livro didático não deve ser menosprezada.

Por não ser elemento de reflexão crítica nos cursos de formação de professores, o livro didático acaba não cumprindo adequadamente seu papel como recurso de apoio, mas orientando inadvertidamente o trabalho do professor em sala de aula. Nóvoa e Vieira (2017, p.22) tocam nesse tema, ao afirmarem que "a expansão de materiais pré-preparados de ensino, muitas vezes produzidos por fundações ou grandes grupos econômicos, $[\ldots]$ condicionam fortemente o trabalho pedagógico e a ação dos professores". É um tipo de discussão que poderia constar nos programas de licenciaturas. A proposta de aumento da carga horária desses cursos, conforme novas Diretrizes Curriculares Nacionais, fixadas pela Resolução $\mathrm{CNE} / \mathrm{CP} \mathrm{n}^{0} 2 / 2015$, que, entre outras providências, passa o mínimo da carga horária de 2.800 para 3.200 horas, distribuídas em oito semestres, com o intento de abrir espaço para atividades mais práticas, pode favorecer algumas discussões suprimidas.

A formação docente inicial deve possibilitar ao professor que enxergue além do roteiro preestabelecido pelo livro didático, que perceba as sutilezas de coerção, que considere as práticas sociais de seus alunos, que trabalhe com o material de modo realmente emancipador, e não permita que o livro seja um fator de limitação de práticas e conteúdos.

É importante reconhecer que, se por um lado, o livro didático traz um saber validado, controlado, padronizado e geralmente em conformidade a uma concepção dominante, por outro, é atualizado em informações e teorias, traz um plano sequencial e atividades. Portanto, é necessário que o professor perceba os pontos negativos que traz o material, a fim de lidar com ele da melhor maneira possível.

A depender de uma formação adequada, do conhecimento adquirido sobre teorias, abordagens e pesquisas sobre ensino e aprendizagem de modo reflexivo, tem-se, como resultado, um profissional engajado em questões políticas e sociais e que tem na 
linguagem um instrumento de transformação. Esse professor pode fazer uso criativo do livro didático, trabalhando com o recurso de modo emancipador e crítico.

Nesse sentido, o Guia do Livro Didático (2017c) também prevê a autonomia do professor em relação ao material, especialmente na seção "na sala de aula" com sugestões de complementação de atividades, de outros textos e caminhos para atingir seus objetivos quanto ao ensino e aprendizagem. O ideal é formar profissionais para o uso do livro didático como instrumento pedagógico e não para que o tomem como fonte de informação e formação. Como validam Nóvoa e Vieira (2017), a prática, por si só, pouco serve, mas refletida, pensada, trabalhada teoricamente, é a mais relevante matéria-prima da formação continuada.

\section{Proposta de análise de livro didático em função da prática docente}

Nossa proposta é trabalhar os conteúdos básicos de língua portuguesa em consonância e de modo comparativo com o Guia (BRASIL, 2017c) 4 , a partir de alguns itens percebidos em cursos que ministramos de formação de professores nos quais pudemos incluir a análise de livro didático como item de nossas ementas.

O olhar do professor é diferente do olhar do avaliador das obras, mesmo que este seja um professor. São lugares sociais assumidos, e o do avaliador exige que se siga um roteiro avaliativo preestabelecido. Já no papel do professor, atuando em sala de aula, no momento da escolha, ou em formação inicial, que tenha em conta esse lugar social do trabalho na escola, há que se pressupor que os livros aprovados no PNLD estejam isentos de qualquer tipo de preconceito ou estereótipo, de qualquer forma de discriminação e de violação dos direitos humanos. Também é presumido que eles já tenham sido avaliados: quanto a preceitos éticos; respeito às diversidades, incluindo a linguística, que contemple diferentes culturas e etnias; que não haja publicidade ou propagação ideológica e religiosa; e que não contenha erros ou induza ao erro. Desse modo, há um pequeno equívoco quando o Guia (BRASIL, 2007c) traz esses questionamentos para que sirvam de parâmetros de avaliação das obras pelos professores. O foco real do professor, de forma efetiva, é analisar se a obra é adequada aos princípios da escola, da comunidade, do seu planejamento de ensino, se condiz com o seu posicionamento teórico e se se adapta aos seus objetivos e às dinâmicas de suas aulas. Sendo assim, mesmo apresentando

4 Para facilitar a leitura, optamos por fazer as chamadas neste texto pelo nome de Guia e PCN, e citaremos a referência entre parênteses. 
v. $8(2)$

$323-343$

mai/ago 2018 critérios de análise similares aos do Guia (BRASIL, 2017c), traremos outra perspectiva. O próprio Guia apresenta uma passagem relativa a esse assunto quando afirma:

Apenas você [professor] poderá avaliar todos os aspectos importantes e atinentes à prática, a serem considerados no ato da escolha do livro didático, como o contexto social em que está inserida a escola, o perfil dos estudantes e as necessidades mais emergentes em relação ao ensino-aprendizagem de Língua Portuguesa; e, ainda, suas próprias demandas (desejos, habilidades) como profissional da educação (BRASIL, 2017c, p.7).

Nossa sugestão para a análise e avaliação do professor, e para estudos nos cursos de formação, é tornar um pouco mais concreta a afirmação acima. Para tanto, iniciamos nossa sugestão de avaliação de obras didáticas pelo professor com a verificação da estrutura física e organizacional de seu conteúdo. O Guia (BRASIL, 2017c) alerta sobre a "clareza e pertinência do modo de agrupar e organizar o desenvolvimento dos conteúdos, em função dos objetivos propostos", ainda mencionando o projeto gráfico, o uso e qualidade das imagens, o agrupamento em capítulos, seções e tópicos (BRASIL, 2017b, p. 14). São observações pertinentes para a apreciação do professor. Para ele, é importante também verificar se a organização em capítulos é adequada à sua dinâmica de aulas; se os conteúdos correspondem, ao menos em parte, aos objetivos de seu plano de ensino ao longo do ano; se esses conteúdos são integrados e contextualmente envolvidos em um tema; se é possível trabalhar os conteúdos associados a uma prática social; se as imagens são plausíveis para discussões, se são reproduções artísticas, se se relacionam com o tema da unidade; se essa estrutura possui um design simples, de fácil entendimento e regular (ver itens I a IV, no Quadro 1).

Quanto aos textos que o livro didático traz para leitura (item V do Quadro 1), importa para o professor que sejam autênticos, que apresentem o suporte em que são originalmente veiculados, que sejam adequados e de interesse dos alunos, variados quanto aos gêneros e suas esferas de circulação, que tragam diferentes posicionamentos sobre uma temática, e que levem a outras leituras. O Guia (BRASIL, 2017c) traz alguns pontos bastante próximos à análise aqui proposta, porém, outros, tais como se a obra apresenta textos representativos de outras culturas e diversidades ou se não há fragmentações e adaptações dos textos originais, já são tópicos vencidos, os quais supostamente já têm uma resposta após terem passado pelo processo avaliativo. 
Cabe ainda observarmos que os objetivos de leitura devem estar claros, fazer sentido para o aluno, ou como melhor aponta Geraldi (1997, p.168) que respondam à questão: "para que se lê o que se lê? ". Além disso, espera-se que esses textos realmente despertem a vontade e o gosto pela leitura, que se constituam enquanto prática social e não sejam somente atividades para atender a uma legitimação social constituída (GERALDI, 1997). Os PCN também trazem considerações sobre a leitura e seus objetivos:

Como se trata de uma prática social complexa, se a escola pretende converter a leitura em objeto de aprendizagem deve preservar sua natureza e sua complexidade, sem descaracterizála. Isso significa trabalhar com a diversidade de textos e de combinações entre eles. Significa trabalhar com a diversidade de objetivos e modalidades que caracterizam a leitura, ou seja, os diferentes "para quês" - resolver um problema prático, informar-se, divertir-se, estudar, escrever ou revisar o próprio texto - e com as diferentes formas de leitura em função de diferentes objetivos e gêneros: ler buscando as informações relevantes, ou o significado implícito nas entrelinhas, ou dados para a solução de um problema (BRASIL, 1997, p. 41).

Quanto às atividades de interpretação (item VI do Quadro 1), ressaltamos a pertinência dos itens da ficha de avaliação do Guia (BRASIL, 2017c), como, por exemplo, exercícios relacionados ao gênero, às estratégias de leitura, aos elementos constitutivos da textualidade. Portanto, espera-se que as atividades propostas no livro didático levem o aluno a entender as condições de produção e os efeitos de sentido que podem ser inferidos e constituídos a partir do texto, e que possibilitem que esse aluno possa se aprofundar na leitura e trazer à tona sua produção responsiva com olhar crítico. Parafraseando Geraldi (2003), a construção de sentidos parte sempre da leitura do texto, que permite criar possibilidades, construir significações; por isso, como aponta o autor, a leitura torna-se "perigosa subversão" numa sociedade onde ela não é uma prática social, onde tradicionalmente é apenas prática de confirmação de uma interpretação prévia imposta.

Quando se trata de leitura, não há como dissociá-la da produção textual. Mais uma vez, tomamos como apoio os PCN:

O trabalho com leitura tem como finalidade a formação de leitores competentes e, conseqüentemente, a formação de escritores, pois a possibilidade de produzir textos eficazes tem sua origem na prática de leitura [...]. A leitura, por um lado, nos fornece a matéria-prima para a escrita: o que escrever. Por outro, contribui para a constituição de modelos: como escrever (BRASIL, 1997, p. 40). 
v. $8(2)$

$323-343$

mai/ago 2018
Do mesmo modo, não se pode promover o ensino e aprendizado da leitura e produção textual sem considerarmos os gêneros e as práticas sociais que a eles se relacionam. Os diversos usos sociais (em esferas específicas) das práticas de escuta e de leitura de textos, das práticas de produção de textos orais e escritos e das práticas de análise linguística, conforme assinaladas nos PCN (BRASIL, 1997) e concebidas nas propostas de Geraldi (1997) para o ensino e a aprendizagem de linguagem nas escolas, têm o gênero como base instrumental (BONINI, 2011).

É por meio dos gêneros que se dá a interação e, portanto, o gênero é componente formador das práticas sociais (BONINI, 2017), e as atividades de leitura já são um momento de reflexão sobre gênero, que depois volta nas atividades de produção textual e análise linguística. Desse modo, trata-se de objeto fundamental do ensino de linguagem. Geralmente, os livros didáticos trazem o ensino dos gêneros e suas características, mas ainda apresentam limites quanto ao ensino da linguagem por meio do gênero.

É também relevante ter objetivos para produzir um texto e esse precisaria ser um tema de reflexão do professor na eleição do livro para seu trabalho (ver item VII do quadro 1). O Guia (BRASIL, 2017c) traz uma questão específica ao professor para que ele observe se a coleção traz objetivos para a produção textual do aluno. Há muito já se tem discutido que não se produz textos apenas para cumprir as solicitações do professor. Assim sendo, é preciso "ter o que dizer" e "para quem dizer" (GERALDI, 1997) a fim de que o processo de produção textual tenha sentido, possibilite ao aluno produzir algo que ele deseja que seja divulgado, lido, valorizado. Logo, a proposta de produção textual precisaria considerar um objetivo de escrita, um interlocutor, o gênero adequado e uma possível divulgação. É fundamental ainda que o processo seja claro ao aluno quanto às características do gênero bem como quanto às etapas de elaboração do texto até a versão final. O Guia (BRASIL, 2017c) também aponta os mesmos elementos. O propósito é formar escritores familiarizados com os usos sociais da língua, com as relações de interlocução, e com as possibilidades de atuação social. 
O saber sobre a escrita estende-se também à produção de textos orais, que naturalmente deveria fazer parte dos conteúdos do livro de forma integrada à leitura e à produção textual escrita. A escola precisa levar em conta que a fala e a escrita são práticas sociais e, assim, proporcionar situações de uso em contextos sociais de fala as mais autênticas possíveis, por meio dos gêneros utilizados na oralidade. A oralidade é ressaltada nos PCN (BRASIL, 1997) e tem um eixo específico no Guia (BRASIL, 2017c), devendo ser objeto de reflexão do professor em termos da avalição e eleição de livro didático para seu trabalho (ver quadro 1, item VII).

No que tange à literatura (ver item VIII do quadro 1), o Guia (BRASIL, 2017c) expõe considerações para avaliação da obra em que se espera que, por já haver passado por avaliação do PNLD, já esteja pressuposta a diversidade de textos, como os africanos, afro-brasileiros, os textos regionais, que tenha variedade de gêneros, que traga indicações de leituras, outras artes associadas e, por fim, que contenha atividades produtivas e diversificadas sobre textos, obras, estilos de época. À parte a isso, cabe ao professor verificar em que sentido esses itens se relacionam com seu planejamento de ensino para ano, como ordenará a exploração do livro escolhido, como complementará com outros textos e atividades, inclusive contemplando aspectos (por exemplo de diversidade cultural) que a obra não abarque.

Com relação ao ensino de gramática, a escola tradicional, com sua ênfase em fórmulas, privilegiou pouco a usabilidade. É mais fácil ensinar a gramática descontextualizada, e foi, por vezes, uma inclinação em um cenário de muitas horas de aula e a busca pelo caminho da acomodação, pois não há surpresas em exemplos decorados. Por outro lado, ensinar os usos da língua em situações pertinentes requer planejamento, e conhecimento dos recursos que compõem um texto em todas as suas artimanhas. O que se espera do aluno da educação básica é que seja experiente nos usos da linguagem e não que decore normas prescritivas gramaticais. A análise linguística tem o propósito de contribuir para o processo da reescrita de textos. O termo surge com Geraldi, que melhor explica sua característica:

A análise linguística inclui tanto o trabalho sobre as questões tradicionais da gramática quanto questões amplas a propósito do texto, entre as quais vale a pena citar: coesão e coerência internas do texto; adequação do texto aos objetivos pretendidos, análise dos recursos expressivos utilizados (metáforas, metonímias, paráfrases, citações, discurso direto e indireto etc.); organização e inclusão de informações etc. (GERALDI, 2003, p.74). 
v. $8(2)$

$323-343$

mai/ago 2018
Diante do exposto, os critérios por nós sugeridos (item IX do Quadro 1) diferem um pouco do Guia (BRASIL, 2017c), que traz como fator avaliativo o que já se presume existir no livro, como promover o ensino das convenções da escrita, conteúdos pertinentes para o nível de ensino, valorização da variedade linguística. As perguntas de avaliação que propomos pressupõem uma reflexão sobre o tipo de abordagem que o livro traz, principalmente se a análise linguística é contextualizada, encarnada em textos e significativa para os enunciados lidos e produzidos.

No que concerne ao manual do professor (item X do Quadro 1), como critério de escolha da obra, cabe observar a opção teórica metodológica que apresenta, se se relaciona com as escolhas teóricas do docente e de que modo. A partir disso, cumpre verificar se o manual ainda é prescritivo e fechado ou se ele fornece possibilidades e sugestões de outras atividades, como indicações de leituras teóricas. Outro ponto que interessa são as respostas dos exercícios; o ideal nesse sentido é que fossem explicativas e em conformidade com a postura teórica metodológica adotada na obra. O Guia (BRASIL, 2017c) questiona sobre a viabilidade de trabalho interdisciplinar, algo que já apontamos no item de organização dos conteúdos (item IV do Quadro 1), mas que vale verificar no manual também.

Essas são sugestões iniciais de discussão com professores ou futuros professores nos cursos de formação. Em nossa experiência com formação de professores, percebemos a ânsia pelo debate da prática, esse compartilhamento de experiências, pode ajudá-lo nas imprevisibilidades do exercício da profissão. Já a teoria colabora com o respaldo das decisões do professor, de sua postura política e ideológica frente aos desafios do ambiente escolar e da comunidade que o cerca. Os cursos de formação ainda são carentes no sentido de possibilitar a reflexão sobre o fazer do professor que atua ou atuará em sala de aula e de como mobilizar a teoria em função da realidade prática.

Apresentamos a seguir um quadro, para melhor visualização, contendo algumas das questões acima discutidas; um quadro que vem sendo utilizado e aperfeiçoado a cada curso de formação inicial e continuada de professores envolvidos com a área da linguagem. 
Quadro 1 - Sugestão de avaliação do livro didático em cursos de formação de professores

\begin{tabular}{|c|c|}
\hline $\begin{array}{l}\text { I. Organização } \\
\text { do livro: } \\
\text { divisão entre } \\
\text { os capítulos }\end{array}$ & $\begin{array}{l}\text { - O formato do livro é agradável? Fácil de } \\
\text { manusear? } \\
\text { - O livro é separado em capítulos (ou unidades)? } \\
\text { Esses capítulos são temáticos? Caso não sejam, qual } \\
\text { o critério utilizado para essa divisão? } \\
\text { É Qual a extensão desses capítulos? Longos? Curtos? } \\
\text { É adequada à dinâmica de suas aulas? } \\
\text { - Esse livro pode te ajudar em seu planejamento? } \\
\text { Ele condiz com a organização do tempo e carga } \\
\text { horária das suas aulas? }\end{array}$ \\
\hline $\begin{array}{l}\text { II. Organização } \\
\text { dos conteúdos } \\
\text { nos capítulos }\end{array}$ & $\begin{array}{l}\text { - Como estão organizados os conteúdos de leitura, } \\
\text { produção textual, gramática e literatura? Eles são } \\
\text { separados ou integrados? } \\
\text { - Essas sistematizações quanto à identificação dos } \\
\text { conteúdos são de simples visualização? } \\
\text { - A organização dos conteúdos vem ao encontro da } \\
\text { prática em sala de aula? } \\
\text { - É possível fazer adaptações que facilitem o ensino } \\
\text { e a aprendizagem a partir da organização desses } \\
\text { conteúdos? }\end{array}$ \\
\hline III. Imagens & $\begin{array}{l}\text { - Como são as imagens do livro, elas são coerentes } \\
\text { com o tema ou com o texto que as acompanha? Ou } \\
\text { são desconexas, apenas ilustram o livro? } \\
\text { - Há imagens de obras de arte ou que se relacionam } \\
\text { a elementos culturais? Há a possibilidade de } \\
\text { trabalhar no sentido de apreciação artística? } \\
\text { - E possível promover discussões a partir delas? } \\
\text { Levar os alunos a reflexões ou podem instigar a } \\
\text { tomada de posicionamentos? }\end{array}$ \\
\hline $\begin{array}{l}\text { IV. Outros } \\
\text { modos de } \\
\text { explorar o } \\
\text { conteúdo }\end{array}$ & $\begin{array}{l}\text { - Há algum indício de envolvimento de outras } \\
\text { disciplinas? Ou seja, há sugestões de trabalho } \\
\text { interdisciplinar viáveis? } \\
\text { - Há algum trabalho com músicas ou filmes? Ou } \\
\text { indicaçoes que levem a outros textos multimodais? } \\
\text { - Há indicações de sites? Como o livro traz as novas } \\
\text { tecnologias para a sala de aula? Há recomendações } \\
\text { de pesquisas? } \\
\text { - Há propostas de projetos que sejam passíveis de } \\
\text { execução na sua escola? }\end{array}$ \\
\hline
\end{tabular}


V. 8 (2)

$323-343$

mai/ago 2018

\begin{tabular}{|c|c|}
\hline V. Leitura & $\begin{array}{l}\text { - O livro traz quantos textos em uma unidade? Você } \\
\text { considera uma boa quantidade, sem excessos ou } \\
\text { faltas? } \\
\text { - O livro instiga a leitura dos textos? Busca ativar o } \\
\text { conhecimento prévio do aluno? Traz, por exemplo, } \\
\text { alguma imagem, manchete ou proposta de diálogo } \\
\text { antes da leitura? } \\
\text { - Os objetivos das leituras dos textos estão claros } \\
\text { para você? Há razões para seus alunos lerem } \\
\text { determinados textos que constam no livro? } \\
\text { - Há variedade de gêneros nos capítulos? Ou } \\
\text { privilegiam um determinado gênero em cada } \\
\text { capítulo? Como se dá o reconhecimento dos gêneros } \\
\text { para os alunos? Há um percurso que demonstra o } \\
\text { caminho das condições de produção daquele gênero? } \\
\text { - Os textos apresentam temáticas interessantes para } \\
\text { a faixa etária dos alunos a que se destina? } \\
\text { - Em um capítulo há uma unica temática ou } \\
\text { há textos com temas variados? Eles fornecem } \\
\text { embasamentos suficientes sobre o tema? Ou trazem } \\
\text { muitas informaçôes incompletas ou desconexas? } \\
\text { - Se os textos se apresentam sobre uma mesma } \\
\text { temática, eles trazem pontos de vista iguais ou } \\
\text { diferentes sobre o assunto? Eles permitem a } \\
\text { construção da opinião crítica, do aluno ou o induzem } \\
\text { a reproduzir o mesmo conteúdo? } \\
\text { - Hấ textos de diferentes esferas de circulação, } \\
\text { como textos jornalísticos, propagandas, literários, } \\
\text { técnicos, de divulgação científica etc.? } \\
\text { - Os textos trazem a referência e o suporte de sua } \\
\text { publicação original? } \\
\text { - Trazem informações relevantes sobre o autor? } \\
\text { - Há outras indicações de fontes de leitura? } \\
\text { - O capítulo traz sugestões de diferentes modos de } \\
\text { leitura que valorizem a escuta e a produção oral de }\end{array}$ \\
\hline $\begin{array}{l}\text { VI. Atividades a } \\
\text { partir do texto }\end{array}$ & $\begin{array}{l}\text { - O livro traz uma quantidade adequada de } \\
\text { atividades de interpretação? } \\
\text { - Essas atividades são somente perguntas e } \\
\text { respostas ou variam em sua estrutura? } \\
\text { - As atividades de interpretação possuem níveis } \\
\text { diferentes de dificuldade? } \\
\text { - Há questões abertas que permitem uma reflexão } \\
\text { crítica sobre o contexto social, político, ideológico, } \\
\text { ético do texto? } \\
\text { - Há questões sobre o gênero? Elas colaboram } \\
\text { na compreensão do texto? Há atividades sobre as } \\
\text { características do gênero que indiquem ao aluno seu } \\
\text { uso corrente e regular nas diversas situações em que } \\
\text { ocorre? } \\
\text { - Traz questões que permitem ao aluno refletir } \\
\text { sobre a construção do sentido do texto? } \\
\text { - Mobiliza reflexão sobre os interlocutores } \\
\text { poșsíveis, leituras previstas e não previstas? } \\
\text { - E possivel adaptar as atividades, caso não estejam } \\
\text { em conformidade com seu planejamento ou } \\
\text { realidade da turma? }\end{array}$ \\
\hline
\end{tabular}




\begin{tabular}{|c|c|}
\hline $\begin{array}{l}\text { VII. Produção } \\
\text { textual }\end{array}$ & $\begin{array}{l}\text { - As propostas de produção textual têm relação com } \\
\text { os textos e/ou com a temática da unidade? } \\
\text { - Os textos forneceram conteúdo suficiente para } \\
\text { o desenvolvimento do tema da redação? Ou seja, o } \\
\text { aluno tem embasamento satisfatório para produzir o } \\
\text { texto que se pede? } \\
\text { - Foram dadas informações suficientes para a } \\
\text { produção do gênero solicitado? Existem exemplos? } \\
\text { - Há indicaçoes de planejamento, realização de } \\
\text { rascunho, revisão e elaboração de nova versão? } \\
\text { - Há, um objetivo, um motivo mais autêntico } \\
\text { possível para que o aluno elabore um texto? Ou a } \\
\text { proposta é artificial, só para produzir uma redação } \\
\text { escolar? } \\
\text { - Há um interlocutor real? } \\
\text { - Há a possibilidade de publicação do texto do } \\
\text { aluno? } \\
\text { - Há solicitações de produção oral, como } \\
\text { seminários, vídeos, músicas, propagandas etc.? } \\
\text { Isso ocorre por meio das explicações sobre esses } \\
\text { gêneros? }\end{array}$ \\
\hline VIII. Literatura & $\begin{array}{l}\text { - O conteúdo referente aos estudos literários é } \\
\text { separado, como um eixo de ensino próprio? Ou } \\
\text { integrado aos demais conteúdos do livro? } \\
\text { - Os estudos literários, seguem tradicionalmente } \\
\text { uma tendência cronológica de estilos de época, } \\
\text { escolas literárias? } \\
\text { - A literatura está direcionada para a formação do } \\
\text { leitor e para os estudos de obras literárias? } \\
\text { - O ensino da literatura ocorre por meio dos } \\
\text { gêneros? } \\
\text { - A literatura contempla escritores africanos e afro- } \\
\text { brasileiros de língua portuguesa? } \\
\text { - Está associada a outras artes, como a pintura, a } \\
\text { escultura, a música, o cinema, o teatro, a dança, a } \\
\text { arquitetura? } \\
\text { - Há indicação de outras obras do mesmo autor ou } \\
\text { época? } \\
\text { - Há propostas de atividades que realmente } \\
\text { provoque no aluno o gosto pela literatura e desejo } \\
\text { pela leitura? } \\
\text { - A proposta de ensino de literatura do livro vai ao } \\
\text { encontro de seus objetivos? }\end{array}$ \\
\hline
\end{tabular}


V. 8 (2)

$323-343$

mai/ago 2018

\begin{tabular}{|l|l|}
\hline IX. Análise & - As atividades de análise linguística partem de um \\
texto ou de uma explicação prescritiva? & - Se as questões têm a ver com o texto, verifique se \\
& o texto é usado como pretexto para as questões ou \\
se elas realmente colaboram para o entendimento & mais profundo do texto. \\
& - Há alguma atividade de menção ou valorização das \\
& variedades, ainda que predomine o ensino na norma \\
padrão? & - As atividades constituem um encadeamento, uma \\
& sequência, ou apresentam-se em exercícios soltos? \\
& - As atividades propostas levam o aluno a \\
& compreender o uso da linguagem em contexto \\
& social escrito ou oral? Ou são atividades mecânicas e \\
descontextualizadas? & - Há textos explicativos sobre os recursos \\
linguísticos? Os exemplos contemplam os textos da \\
unidade? \\
- O livro traz a possibilidade de adaptação das \\
atividades para o contexto de uso mais autêntico, \\
mais próximo do cotidiano do aluno?
\end{tabular}

Fonte: elaborado pelos autores.

\section{Considerações Finais}

Tendo por finalidade contribuir com as discussões sobre a formação docente, no que se refere à análise, escolha e uso do livro didático, bem como propiciar uma fonte de leitura e pesquisa para professores que atuam com o livro didático de língua portuguesa no ensino médio, abordamos brevemente as políticas públicas que envolvem o contexto do livro didático, discutimos seu uso em relação à formação do professor e, por fim, apresentamos uma sugestão de análise e avaliação do material com base no Guia do Livro Didático do PNLD de 2018, nos Parâmetros Curriculares Nacionais e estudiosos dos conteúdos língua portuguesa. 
Háainda uma lacuna nos cursos de formação inicial e continuada de professores de língua portuguesa em relação ao uso do livro didático. A expectativa não é o abandono do material, mas a utilização crítica de um recurso disponível e acessível no ambiente escolar, o que não impede a construção do conhecimento sobre o ensino e aprendizagem da língua portuguesa, ao contrário espera-se que o material seja mais um apoio para a reflexão sobre novas práticas pedagógicas. Portanto, ainda carecemos de pesquisas que tratem da formação mais prática do professor de língua portuguesa, que explorem mais os recursos didáticos ao nosso alcance, que continuem contribuindo para a melhora da qualidade dos materiais didáticos.

\section{Referências}

ANTUNES, C. 0 uso inteligente dos livros didáticos e paradidáticos. São Paulo: Paulus, 2012.

BATISTA, A. C. G. Recomendações para uma política do livro didático. Brasília: Ministério da Educação, Secretaria de Educação Fundamental, 2001.

BONINI. A. O jornal escolar como mídia contra-hegemônica - jornalismo de escola não modelado pelo jornalismo comercial dominante. Linguagem em (Dis)curso - LemD, Tubarão, SC, v. 17, n. 2, p. 165-182, maio/ago. 2017.

BONINI. A. Jornal escolar: gêneros e letramento midiático no ensinoaprendizagem de linguagem. RBLA, Belo Horizonte, v. 11, n. 1, p. 149-175, 2011.

BRASIL. Fundo Nacional de Desenvolvimento da Educação (FNDE). Programas / PNLD / Histórico. Disponível em: <http://www.fnde.gov.br/programas/ programas-do-livro/livro-didatico/historico>. Acesso em: 27 set. 2017.

BRASIL. Fundo Nacional de Desenvolvimento da Educação (FNDE). PNLD / Dados estatísticos. Disponível em: <http://www.fnde.gov.br/programas/ livro-didatico/livro-didatico-dados-estatisticos>. Acesso em: 1 maio, 2017a.

BRASIL. Ministério da Educação. Assessoria de comunicação social. Livro didático. Escolha dos livros aprovados pelo PNLD 2018 começa dia 21. Disponível em: $\quad<$ http://portal.mec.gov.br/ultimas-noticias/211-218175739/52611escolas-escolherao-livros-aprovados-pelo-pnld-2018-a-partir-do-dia-21>. Acesso em 1 out. 2017b.

BRASIL. Ministério da Educação. PNLD 2018: língua portuguesa - guia de livros didáticos - Ensino Médio/ Ministério da Educação - Secretária de Educação Básica - SEB - Fundo Nacional de Desenvolvimento da Educação. Brasília, DF: Ministério da Educação, Secretária de Educação Básica, 2017c.

BRASIL. Conselho Nacional de Educação. Resolução CNE/CP n.02/2015, de $1^{0}$ de julho de 2015. Brasília, Diário Oficial [da] República Federativa do Brasil, seção 1, n. 124, p. 8-12, 02 de julho de 2015. 
V. $8(2)$ $323-343$ mai/ago 2018

BRASIL. Fundo Nacional de Desenvolvimento da Educação (FNDE). Edital PNLD 2018. Edital de convocação 04/2015 - CGPLI. 2015a. Disponível em: <http://www.fnde.gov.br/programas/programas-do-livro/consultas/editaisprogramas-livro/item/7932-pnld-2018>. Acesso em: 6 out. 2017.

BRASIL. Ministério da Educação. Secretaria de Educação Básica. Secretaria de Educação Continuada, Alfabetização, Diversidade e Inclusão. Conselho Nacional da Educação. Diretrizes Curriculares Nacionais Gerais da Educação Básica. Brasília: MEC, SEB, DICEI, 2013.

BRASIL. Secretaria de Educação Fundamental. Introdução aos parâmetros curriculares nacionais. Secretaria de Educação Fundamental. Brasília: MEC/SEF, 1997.

BRASIL. [Lei Darcy Ribeiro (1996)]. LDB nacional [recurso eletrônico]: Lei de diretrizes e bases da educação nacional: Lei $n^{\circ}$ 9.394, de 20 de dezembro de 1996, que estabelece as diretrizes e bases da educação nacional. - 11. ed. - Brasília: Câmara dos Deputados, Edições Câmara, 2015. - (Série legislação; n. 159). 1996.

BRASIL. Decreto-lei no 8.060, de 26 de Dezembro de 1945. Consolida a legislação sobre as condições de produção, importação e utilização do livro didático. Disponível em: <http://www2.camara.leg.br/legin/fed/declei/1940-1949/ decreto-lei-8460-26-dezembro-1945-416379-publicacaooriginal-1-pe. html>. Acesso em: 9 nov. 2017.

BRASIL. Decreto-Lei no 1.006, de 30 de Dezembro de 1938. Estabelece as condições de produção, importação e utilização do livro didático. Disponível em: <http://www2.camara.leg.br/legin/fed/declei/1930-1939/decreto-lei1006-30-dezembro-1938-350741-publicacaooriginal-1-pe.html>. Acesso em: 9 nov. 2017.

CASSIANO, C. C. de F. O mercado do livro didático no Brasil: da criação do Programa Nacional do Livro Didático (PNLD) à entrada do capital internacional espanhol (1985-2007). 2007. 252 f. Tese (Doutorado em Educação) - Programa de Estudos Pós-Graduados em Educação: História, Política Sociedade. Pontifícia Universidade Católica de São Paulo, São Paulo, 2007.

CORACINI, M. J. R F. Interpretação, autoria e legitimação do livro didático. Campinas: Pontes, 1999.

DIONÍSIO, Â. P.; BEZERRA, M. A. (Orgs.). o livro didático de português: múltiplos olhares. 2. ed. Rio de Janeiro: Lucerna, 2003.

FARIA, A. L. G. de. Ideologia no livro didático. São Paulo: Atlas, 1998.

FREITAG, B.; MOTTA, V. R.; COSTA, V. F. 0 estado da arte do livro didático no Brasil. Instituto Nacional de Estudos e Pesquisas Educacionais (INEP); Rede Latinoamericana de Informação e Documentação em Educação (REDUC): Brasília: 1987.

GERALDI, J. W. (org.) 0 texto na sala de aula. 3. ed. São Paulo: Ed. Ática, 2003.

GERALDI, J. W. Portos de Passagem. 4. ed. São Paulo: Martins Fontes, 1997.

KLEIMAN, Ângela B. Letramento e suas implicações para o ensino de língua materna. Signo, Santa Cruz do Sul, RS, v. 32, n. 53, p. 1-25, 2007. Disponivel em: <http://online.unisc.br/seer/index.php/signo/article/viewFile/242/196>. Acesso em: 22 jan. 2018. 
LAJOLO, M. Livro didático: um (quase) manual de usuário. Em Aberto, Brasília, ano 16, no 69, jan/mar, 1996.

MUNAKATA, K. O livro didático como mercadoria. Pro-Posições. v. 23, n $\mathrm{n}^{0} 3$ (69) set./dez. 2012. Disponível em: <http://www.scielo.br/pdf/pp/v23n3/04. pdf $>$. Acesso em: 8 out. 2017.

MUNAKATA, K. Livro didático como indício da cultura escolar. Hist. Educ. (Online) Porto Alegre, v. 20, n. 50, set./dez., 2016. Disponível em: <www. scielo.br/pdf/heduc/v20n50/2236-3459-heduc-20-50-00119.pdf>. Acesso em 1 out. 2017.

NOSELLA, M. de L. C. D. As belas mentiras: a ideologia subjacente aos textos didáticos. 5. ed. São Paulo: Moraes, 1981.

NÓVOA, António; VIEIRA, Pâmela. Um alfabeto da formação de professores. Crítica Educativa (Sorocaba/SP), v. 3, n. 2 - Especial, p. 21-49, jan./jun. 2017. Disponível em: <http://www.criticaeducativa.ufscar.br/index.php/ criticaeducativa/article/view/217>. Acesso em: 6 out. 2017.

ROJO, R. H. R.; BATISTA, A. A. G. (Org.). Livro didático de Língua Portuguesa, letramento e cultura da escrita. Campinas: Mercado de Letras, 2003. 